\title{
EFICIÊNCIA DE ARGILA SILICATADA NO CONTROLE DE Xanthomonas axonopodis PV. passiflorae, IN VITRO E EM MUDAS DE MARACUJAZEIRO-AMARELO ${ }^{1}$

\author{
PRISCILA BRANCAGLIONE ${ }^{2}$, ALOÍSIO COSTA SAMPAIO ${ }^{3}$, IVAN HERMAN FISCHER ${ }^{4}$, \\ APARECIDA MARQUES DE ALMEIDA ${ }^{4}$, TEREZINHA DE FÁTIMA FUMIS ${ }^{3}$
}

\begin{abstract}
RESUMO-A mancha bacteriana do maracujá, causada pela bactéria Xanthomonas axonopodis pv. passiflorae, ocorre em todas as regiões produtoras do País, sendo responsável por grandes perdas econômicas na cultura do maracujazeiro-amarelo. O presente trabalho teve como objetivos testar a eficiência de argila silicatada na inibição da bactéria $X$. axonopodis pv. passiflorae in vitro e no controle preventivo e curativo da mancha bacteriana em mudas de maracujazeiro-amarelo. A argila silicatada foi adicionada ao meio de cultura batata-dextrose-ágar fundente, nas concentrações de 0,$0 ; 0,5 ; 1,0 ; 1,5$ e 2,0\%; vertido em placas de Petri. Após resfriamento do meio, repicou-se a suspensão bacteriana $\left(10^{7} \mathrm{UFC} . \mathrm{mL}^{-1}\right)$ com uma alça, incubando-se as placas a $28^{\circ} \mathrm{C}$ por três dias, quando se avaliou o crescimento bacteriano. Posteriormente, o produto, nas mesmas concentrações citadas, foi pulverizado em mudas de maracujá 'Afruvec' de forma preventiva ou curativa. A inoculação da bactéria foi realizada através de pulverização foliar da suspensão bacteriana $\left(10^{7} \mathrm{UFC} . \mathrm{mL}^{-1}\right), 24 \mathrm{~h}$ antes ou após os tratamentos curativo e preventivo, respectivamente. A severidade da doença foi avaliada com auxílio de uma escala diagramática nas quatro primeiras folhas verdadeiras contadas de baixo para cima. Nas concentrações avaliadas, a argila silicatada inibiu a bactéria in vitro e os sintomas da mancha bacteriana no tratamento curativo, enquanto no tratamento preventivo, controle significativo foi obtido a partir de $1,0 \%$ de argila silicatada. Com base nestes resultados, a argila silicada pode ser recomendada, na concentração de 1,0-2,0\%, para o controle da mancha bacteriana do maracujazeiro em pulverizações foliares.
\end{abstract}

Termos para indexação: Passiflora edulis, bacteriose, manejo, silício.

\section{ANALYSIS OF THE EFFICIENCY OF SILICATE CLAY ON THE CONTROL OF Xanthomonas axonopodis PV. passiflorae IN VITRO AND IN SEEDLINGS OF YELLOW PASSION FRUIT CONTAMINATED}

\begin{abstract}
The bacterial spot in yellow passion fruit plants, caused by the bacteria Xanthomonas axonopodis pv. passiflorae, occurs in all producing areas of the country, and is responsible for great economic losses in the culture of passion fruit. This study aimed to test the efficiency of the silicate clay in the inhibition of the bacteria Xanthomonas axonopodis pv. passiflorae in vitro, and in both preventive and curative control of the bacterial spot in seedlings of yellow passion fruit plants. The silicate clay was added to the growth medium at concentrations of: $0.5,1.0,1.5$ and 2.0\%, placed in Petri dishes. After the culture medium was cooler, the bacterial suspension was inoculates $\left(10^{7} \mathrm{UFC} \cdot \mathrm{mL}^{-1}\right)$ with a handle, and left incubating at $28^{\circ} \mathrm{C}$ for three days, and then the bacterial growth was evaluated. Subsequently, the product at the same concentrations above was sprayed on seedlings of 'Afruvec' passion fruit, as preventive or curative. The inoculation of the bacteria was made by foliar spraying of bacterial suspension $\left(10^{7} \mathrm{ufc} \cdot \mathrm{mL}^{-1}\right), 24$ hours before or after the curative and preventive treatments, respectively. The severity of the disease was measured comparing each four true leaves from bottom up, with a diagrammatic scale. In the concentrations evaluated, the silicate clay inhibited both bacteria in vitro and symptoms of bacterial spot in the curative treatment. In preventive treatment, significant results were obtained using more than $1.0 \%$ of clay silicates. Based on these results, the clay silicate can be recommended, the concentration of 1.0-2.0\% for the control of bacterial spot of passion fruit plants, in foliar sprays.
\end{abstract}

Index terms: Passiflora edulis, bacterial, management, silicon.

\footnotetext{
$\overline{1}$ (Trabalho 136-08). Recebido em: 02-06-2009. Aceito para publicação em: 14-05-2009.

${ }^{2}$ Bióloga, Trabalho de Conclusão de Curso em Ciências Biológicas - UNESP/FC/Bauru. email: pbrancaglione@gmail.com ${ }^{3}$ Docentes do Departamento de Ciências Biológicas - UNESP/FC/Bauru. emails: aloisio@fc.unesp.br ; tffumis@fc.unesp.br ${ }^{4}$ Pesquisadores da Unidade de Pesquisa e Desenvolvimento de Bauru - APTA Centro-Oeste. emails: ihfische@apta.sp.gov.br ; almeida@apta.sp.gov.br)
} 


\section{INTRODUÇÃO}

O Brasil é o maior produtor e consumidor mundial de maracujá, possuindo 35.820 ha de área colhida em 2005 (Agrianual, 2008). O maracujáamarelo ou azedo (Passiflora edulis Sims f. flavicarpa Deg.) representam cerca de $97 \%$ dessa área e do volume comercializado em todo o País. Estima-se que mais de $60 \%$ da produção brasileira de maracujá-amarelo sejam destinados ao consumo in natura (Rossi, 2005).

Uma das principais doenças do maracujazeiro é a mancha bacteriana, causada por Xanthomonas axonopodis pv. passiflorae (Pereira) Dye que se apresenta como um fator limitante para a cultura, em várias regiões produtoras do Brasil, em virtude da forma severa com que ocorre sob condições de clima quente e úmido. Diversas medidas têm sido recomendadas para o controle da bacteriose, como a produção de mudas sadias, erradicação das porções vegetais doentes, uso de quebra-ventos e aplicação de produtos com ação bactericida. No entanto, essas medidas não têm apresentado resultados satisfatórios (Miranda, 2004), causando, consequentemente, aumento de custos ao produtor, prejuízos ao meio ambiente e à saúde humana (Altieri \& Nicholls, 2000). Considerando-se que essa doença leva à redução da produtividade do maracujazeiro, é de fundamental importância que sejam realizadas pesquisas visando ao seu controle.

Dentro do contexto atual do mercado de frutas, há a Produção Integrada (PI) como um dos exemplos de maior sucesso. As maiores diferenças em relação à produção convencional são encontradas no manejo fitossanitário (Oliveira, 2002). Na PI, esse manejo é baseado em normas e leis regionais, respeitando os níveis de dano econômico, amostragem, nível de doença e sistemas de previsão, enquanto no sistema convencional é mais comum o uso de calendário preestabelecido de pulverizações (Oliveira, 2002).

Resultados satisfatórios em relação à atuação de produtos naturais, como o silício, no controle de fitopatógenos, vêm sendo constatados. Uma das técnicas utilizadas consiste em pulverizações do pó de rocha ou silício nas folhas (Waldemar Filho et al., 2007).

O mecanismo pelo qual o silício afeta o desenvolvimento das doenças em plantas é possivelmente resultado da ação deste elemento no tecido do hospedeiro, proporcionando impedimento físico e maior acúmulo de compostos fenólicos e lignina no local da injúria (Chérif et al., 1992). O efeito preventivo consiste na proteção dada à planta através da aplicação do produto antes da exposição a um patógeno, enquanto o efeito curativo se mostra como a reparação ou a diminuição dos efeitos causados pelo patógeno à planta (Santos \& May de Mio, 2007).

Desse modo, objetivou-se, com este trabalho, analisar a eficiência de argila silicatada na inibição da bactéria $X$ axonopodis pv. passiflorae in vitro e no controle preventivo e curativo da mancha bacteriana em mudas de maracujazeiro-amarelo 'Afruvec'.

\section{MATERIAL E MÉTODOS}

Os experimentos foram realizados na Agência Paulista de Tecnologia dos Agronegócios, Polo Centro-Oeste, Bauru. As três estirpes da bactéria $X$. axonopodis $\mathrm{pv}$. passiflorae utilizadas foram isoladas de folhas doentes de maracujazeiro-amarelo, segundo metodologia de Ferreira \& Salgado (1995), duas procedentes de um pomar de Bauru-SP, e outra de um pomar de Brasília-DF. Foram avaliadas quatro concentrações de argila silicatada, de acordo com as recomendações do fabricante do produto comercial (Rocksil@).

Efeito in vitro da argila silicatada sobre Xanthomonas axonopodis pv. passiflorae

A argila silicatada foi diluída em série e ajustada para as concentrações de 0,$0 ; 0,5 ; 1,0 ; 1,5$ e $2,0 \%$, adicionada ao meio de cultura batata-dextrose-ágar fundente, a $45-50 \mathrm{oC}$, com $20 \mathrm{~mL}$ vertidos em cada placa de Petri de $90 \mathrm{~mm}$ de diâmetro. Após resfriamento do meio, transferiu-se uma gota $(40 \mu \mathrm{L})$ da suspensão bacteriana com $10^{7}$ UFC. $\mathrm{mL}^{-1}$, segundo escala de Mcfarland (Mariano, 2000). Cada placa foi enumerada em sua parte externa de 1 a 3, representando as 3 estirpes avaliadas, para marcar o local a ser adicionada a suspensão bacteriana. Estes números foram repetidos na direção oposta ao seu semelhante, para que houvesse duas repetições de cada estirpe por placa.

As placas permaneceram a uma temperatura aproximada de $28 \mathrm{oC}$, no escuro, por um período de três dias. A eficiência do produto foi verificada através do crescimento ou não da colônia bacteriana. $\mathrm{O}$ delineamento experimental foi o inteiramente casualizado, com cinco placas (repetições) para cada concentração de argila silicatada, sendo cada parcela representada por uma placa de Petri. O experimento foi repetido em período diferente. 
Efeito da argila silicatada no controle preventivo e curativo da mancha bacteriana em mudas de maracujazeiro-amarelo

Mudas de maracujazeiro-amarelo 'Afruvec', com 130 dias após a semeadura, foram submetidas a tratamento com argila silicatada no interior de estufa telada. Foram utilizadas 24 mudas nos tratamentos preventivo e curativo, sendo 4 mudas para o controle e 5 para os tratamentos com argila silicatada $(0,5$; 1,$0 ; 1,5$ e $2,0 \%$ ). Neste experimento, empregou-se apenas uma estirpe de $X$. axonopodis pv. passiflorae procedente de Bauru-SP.

\section{Controle preventivo}

As mudas foram tratadas com argila silicatada através de pulverizações foliares até o ponto de escorrimento. No dia seguinte, pulverizaram-se as mesmas com a suspensão bacteriana, na concentração de $10^{6}$ UFC.mL ${ }^{-1}$, com posterior implantação de câmara úmida com saco plástico por 24 horas. Em seguida, cortou-se aproximadamente $1 \mathrm{~cm}$ das extremidades das folhas das mudas com uma tesoura para favorecer a penetração do patógeno, retornando à câmara úmida por mais 24 horas (Miranda, 2004).

\section{Controle curativo}

Assim como no teste preventivo, a bactéria foi inoculada por meio de pulverização da suspensão bacteriana na concentração de $10^{6} \mathrm{UFC} \cdot \mathrm{mL}^{-1} \mathrm{e}$, logo em seguida, realizou-se câmara úmida. Um dia após a inoculação das mudas, as mesmas receberam os tratamentos com argila silicatada, retornando ao mesmo local. Após seis horas, cortaram-se as extremidades das folhas, retornando novamente à câmara úmida por mais $18 \mathrm{~h}$, a fim de se completar o período de $48 \mathrm{~h}$ de câmara úmida, favorável à penetração da bactéria no hospedeiro (Miranda, 2004).

\section{Avaliação do experimento}

As avaliações foram realizadas no $13^{\circ} ; 15^{\circ}$; $17^{\circ} ; 20^{\circ}$ e $22^{\circ}$ dias após a inoculação da bactéria, analisando-se as quatro primeiras folhas verdadeiras contadas de baixo para cima e calculando-se a severidade média em cada planta (repetição). Para avaliar a severidade da doença, foi utilizada uma escala diagramática elaborada por Miranda (2004), feita especificamente para a mancha bacteriana do maracujazeiro. Esta escala apresenta cinco níveis de severidade, sendo o menor nível correspondente a uma severidade de $2 \%$ e o maior nível de $59 \%$. Os níveis intermediários obedecem à lei de acuidade visual de Weber-Fechner (Nutter \& Schultz, 1995), correspondendo a $5 \% ; 11 \%$ e $26 \%$ de severidade. Os dados de severidade no $22^{\circ}$ dia de avaliação foram analisados por meio de análise de regressão quadrática, por apresentar maior índice de correlação entre as variáveis estudadas.

\section{RESULTADOS E DISCUSSÃO}

Efeito in vitro da argila silicatada sobre Xanthomonas axonopodis pv. passiflorae

A argila silicatada inibiu em $100 \%$ o crescimento bacteriano, em meio de cultura, em todas as concentrações empregadas $(0,5$ a $2 \%)$, o que confirma o efeito positivo de controle do produto sobre as bactérias (Figura 1).

Os resultados obtidos corroboram os de Albuquerque \& Uesugi (2000), em um experimento semelhante, utilizando a bactéria Xanthomonas axonopodis pv. citri, cuja inibição foi obtida nas concentrações superiores a $1 \%$.

\section{Efeito da argila silicatada no controle preventivo e curativo da mancha bacteriana em mudas de maracujazeiro-amarelo}

Através das análises de regressão (Figuras 2 e 3), pode-se observar o efeito significativo das diferentes concentrações de argila silicatada utilizadas em ambos os sistemas de tratamento.

Após 22 dias da inoculação de $X$. axonopodis pv. passiflorae nas mudas de maracujazeiroamarelo, as plantas de ambos os tratamentos, preventivo e erradicante, não apresentaram sintomas de danos significativos (Figuras $4 \mathrm{a}$ e $4 \mathrm{~b}$ ). Mediante a análise de regressão da última avaliação $\left(22^{\circ} \mathrm{dia}\right)$, notou-se que, no tratamento preventivo, as diferentes concentrações de argila silicatada controlaram a mancha bacteriana, com destaque para as três maiores concentrações $(1,0$ a 2,0\%), que apresentaram diferenças significativas em relação aos demais tratamentos (Figura 4a). Já no tratamento curativo, todas as concentrações do produto foram eficientes no controle da doença, diferindo estatisticamente da testemunha, sendo que as duas maiores concentrações $(1,5$ e $2,0 \%)$ diferiram significativamente das menores $(0,5$ e $1,0 \%)$ (Figura $4 b)$.

Resultados semelhantes foram observados por Santos (2002) e Pratissoli et al. (2007), que constataram um decréscimo linear na severidade da cercosporiose do cafeeiro (Cercospora coffeicola Berkeley \& Cooke) e da varíola do mamoeiro (Asperisporium caricae (Speg.) Maub. com a aplicação de silicatos de cálcio e argila silicatada. Plantas de arroz (Oryza sativa L.), cultivadas com 
doses crescentes desse elemento, também tiveram a severidade da queima-das-bainhas (Rhizoctonia solani Kühn) reduzida (Rodrigues et al., 2002). Entretanto, pesquisas envolvendo o controle de doenças bacterianas em plantas ainda são escassas. Plantas de fumo (Nicotiana tabacum L.) tratadas com metassilicato apresentaram redução de sintomas da doença causada pela bactéria Xylella fastidiosa subsp. pauca Shaad, indicando que o silício poderá ser útil no controle da clorose variegada dos citros.

Possivelmente, os mecanismos pelos quais o silício esteja controlando a bacteriose seja uma ação direta contra o patógeno, como constatado no teste in vitro, e também por indução de resistência na planta do maracujazeiro, seja por barreiras estruturais, como o acúmulo desse elemento na parede das células da epiderme e da cutícula, tornando-as menos acessíveis às enzimas de degradação (Barbosa Filho et al., 2000; Korndorfer \& Pereira, 2001), seja por acúmulo no local de penetração do patógeno (Rodrigues et al., 2003) ou por ativar barreiras químicas e bioquímicas das plantas, favorecendo maior acúmulo de compostos fenólicos e peroxidases no local da injúria (Bélanger et al., 2003). Nesse mesmo sentido, Pozza et al. (2004) observaram que o aumento da resistência do cafeeiro (Coffea arabica L.) à cercosporiose foi devido ao maior espessamento da cutícula e ao aumento da absorção de micronutrientes pelas plantas trata- das com silício. Essa hipótese foi constatada através de imagens em microscopia eletrônica de varredura, nas quais observaram a presença de uma cutícula mais espessa cobrindo parcialmente os estômatos na superfície inferior da folha das mudas de cafeeiro tratadas com silicato de cálcio no solo. Os autores observaram que o espessamento da cutícula, devido principalmente à formação de uma camada de cera epicuticular mais espessa, dificultou a penetração do patógeno diretamente através da cutícula ou pelos estômatos.

$\mathrm{O}$ emprego de produtos ativadores de mecanismos de defesa das plantas ("resistência adquirida") representa uma importante abordagem a ser considerada no controle de fitopatógenos (Duval et al., 2005). Sendo assim, o uso de argilas silicatadas poderá contribuir de forma significativa para a redução no uso de defensivos agrícolas convencionais e, com isso, amenizar o impacto ambiental destes produtos de forma econômica, visando à sustentabilidade da produção.

Contudo, para se obterem bons resultados do efeito de fontes silicatadas no aumento da resistência de plantas a patógenos, é necessário suprimento contínuo desses elementos (Bélanger \& Menzies, 2003). Sendo assim, para se reduzir a severidade da mancha bacteriana do maracujazeiro, deve-se manter periodicidade nas aplicações, juntamente com outras alternativas viáveis de controle, que permitam a sustentabilidade do agroecossistema envolvido.

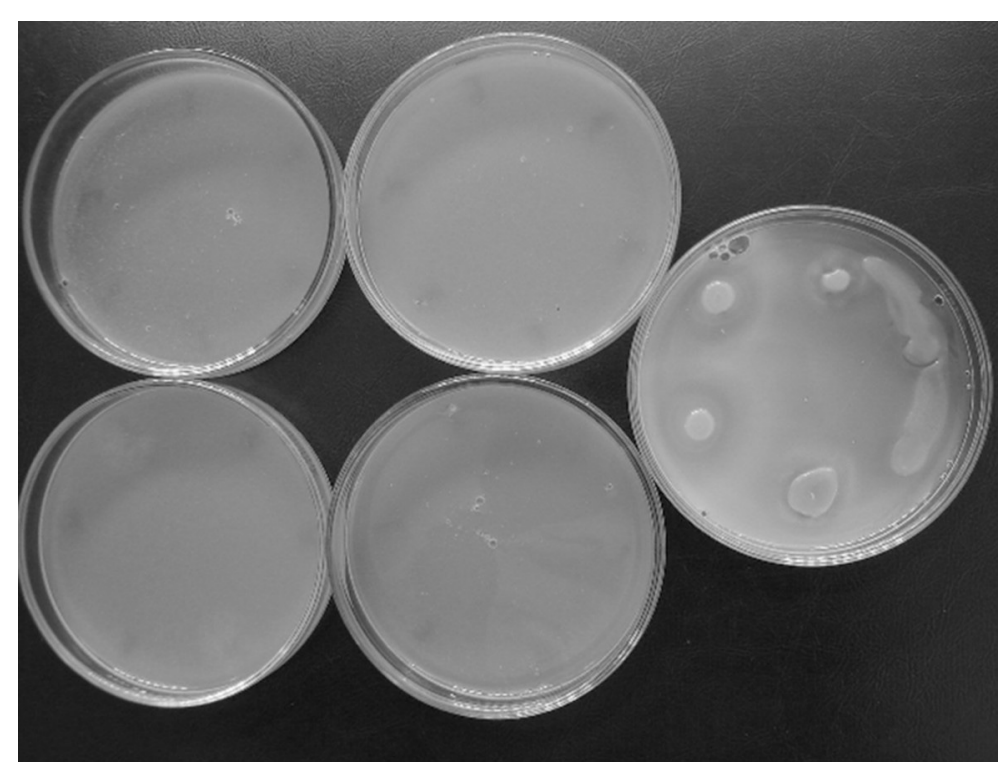

FIGURA 1 - Meios de cultura com as quatro concentrações de ROCKSIL $®$ e o controle (placa a direita) Bauru (SP). 


\section{Preventivo}

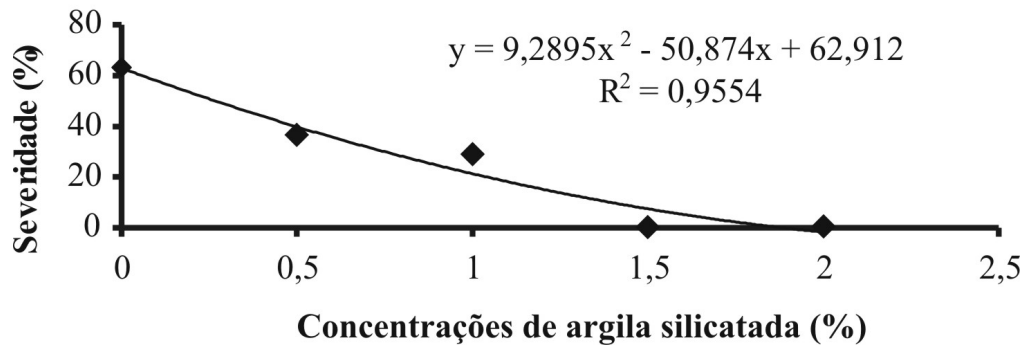

FIGURA 2 - Severidade (\%) da mancha bacteriana em folhas de maracujazeiro-amarelo em tratamento preventivo com argila silicatada, 22 dias após a inoculação da bactéria Xanthomonas axonopodis pv. passiflorae. $(\rho=0,04$; erro-padrão da média $=7,90)$.

\section{Curativo}

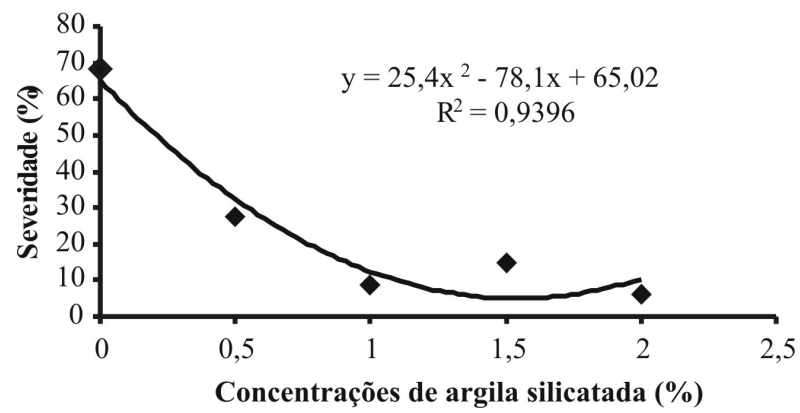

FIGURA 3-Severidade (\%) da mancha bacteriana em folhas de maracujazeiro-amarelo em tratamento curativo com argila silicatada, 22 dias após a inoculação da bactéria Xanthomonas axonopodis pv. passiflorae. $(\rho=0,0603$; erro-padrão da média $=8,830)$.

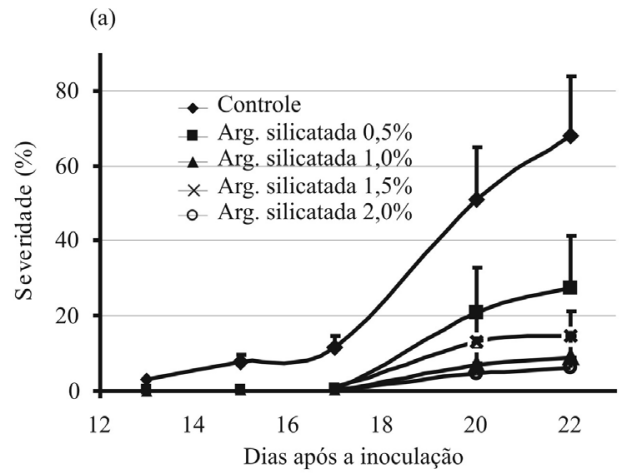

(b)

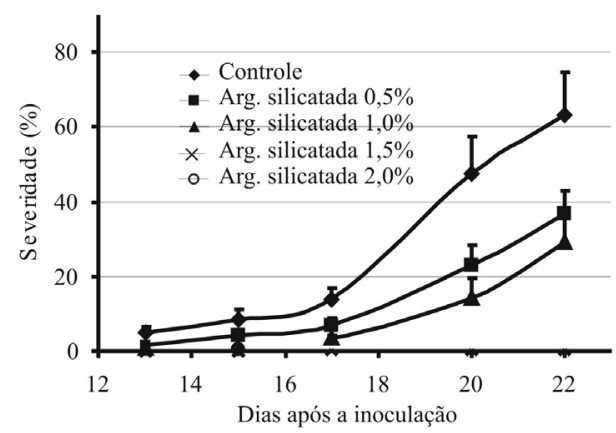

FIGURA 4 - Progresso da severidade (\%) da mancha bacteriana em folhas de maracujazeiro-amarelo após a inoculação da bactéria Xanthomonas axonopodis pv. passiflora, em tratamento preventivo (a) e curativo (b) com argila silicatada. 


\section{CONCLUSÕES}

que:

Pelos resultados obtidos, pode-se concluir

1-Todas as concentrações de argila silicatada avaliadas $(0,0 ; 0,5 ; 1,0 ; 1,5$ e $2 \%)$ apresentaram eficiência no controle da bactéria Xanthomonas axonopodis pv. passiflorae in vitro.

2-A argila silicatada pode ser recomendada no controle preventivo e curativo da mancha bacteriana do maracujazeiro, através de pulverizações foliares nas concentrações entre 1,0 e $2,0 \%$.

\section{REFERÊNCIAS}

AGRIANUAL 2008: anuário estatístico da agricultura brasileira. São Paulo: FNP Consultoria e Comércio, 2008. p. 388.

ALBUQUERQUE, R. C.; UESUGI, C. H. Inibição in vitro de Xanthomonas axonopodis pv. citri por Rocksil, um protetor de planta não tóxico. In: CONGRESSO BRASILEIRO DE FITOPALOGIA, 25., 2000, Belém. Resumos... p.318.

ALTIERI, M.; NICHOLLS, C. I. Agroecología: teoria y practica para una agricultura sustentable. Mexico: Pnuma/Orpalc, 2000. p.250 (Série Textos Básicos para la Formácion Ambiental).

BARBOSA FILHO, M. P.; SNYDER, G. H.; PRABHUL, A.S.; DATNOFF, L. E.; KORNDORFER, G. H. Importância do silício para a cultura do arroz (uma revisão de literatura). Informações Agronômicas, Piracicaba, n.89, 2000.

BÉLANGER, R. R.; BENHAMOU, N.; MENZIES, J. G. Mineral nutrition in the management of plant diseases. Phytopathology, Lancaster, v.93, n.3, p.402-412, 2003.

CHÉRIF, M.; MENZIES, J. G.; BENHAMOU, N.; BÉLANGER, R. R. Studies of silicon distribution in wounded and Pythium ultimum infected cucumber plants. Physiological and Molecular Plant Pathology, London, v.41, p.371-385 1992.

DUVAL, A. M. Q.; LOPES, C. A.; JUNQUEIRA, N. T. V. Avaliação de produtos alternativos para o controle da mancha-bacteriana em tomateiro para processamento industrial. Brasilia: Embrapa Hortaliças, 2005. p.5 . (Circular Técnica)
FERREIRA L. P.; SALGADO, C. L. Bactérias. In: Bergamin Filho, Armando; Kimati, H. H. Manual de fitopatologia. 3. ed., São Paulo: Agronômica Ceres. 1995. v. 1, p.97-131.

KORNDÖRFER, G.H.; PEREIRA, H.S. Papel do silício na citricultura. Revista Citricultura Atual, Cordeirópolis, SP, v. 4, n. 25, p.16-18, 2001.

MARIANO, R. Manual prático em fitobacteriologia. Recife: Universidade Federal de Pernambuco, 2000. 171p.

MIRANDA, J. F. Reação de variedades de maracujazeiro-amarelo (Passiflora edulis Sims f. flavicarpa Deg.) a bacteriose causada por Xanthomonas campestris pv. passiflorae. 2004. 48f. Dissertação (Mestrado em Agronomia, área de concentração: Fitopatologia) - Escola Superior de Agricultura "Luiz de Queiroz", Universidade de São Paulo, Piracicaba, 2004.

NUTTER Jr., F.W.; SCHULTZ, P.M. Improving the accuracy and precision of disease assessments: selection of methods and use of computer-aided training programs. Canadian Journal of Plant Pathology, Ottawa, v.17, p.174-184, 1995.

OLIVEIRA, V. H. Produção Integrada de Frutas: conceitos básicos. In: CURSO DE CAPACITAÇÃO EM PRODUÇÃO INTEGRADA DE FRUTAS, 2002, Fortaleza. Curso de Capacitação em Produção Integrada de Frutas... Disponível em: <http:// caju.cnpat.embrapa.br/pif/Publicacoes/Apostila_PIF. pdf>. Acesso em: 30 out. 2007.

POZZA, A. A. A.; ALVES, E.; POZZA, E. A.; CARVALHO, J. G.; MONTANARI, M.; GUIMARÃES, P. T. G.; SANTOS, D. M. Efeito do silício no controle da cercosporiose em três variedades de cafeeiro. Fitopatologia Brasileira, Brasília, v.29, p. $185-188,2004$.

PRATISSOLI, D.; ALMEIDA, G.D.; JESUS JR, W. C.; VICENTINI, V.B., HOLTZ, A.M.; COCHETO, J.G. Fertilizante organomineral e argila silicatada como indutores de resistências à varíola do mamoeiro. IDESIA, Chile, v.25, n.2, p.63-67, 2007.

RODRIGUES, F. A.; BENHAMOU, N.; DATNOFF, L. E.; JONES, J. B.; BÉLANGER, R. R. Ultrastuctural and cytochemical aspects of silicon-mediated rice blast resistance. Phytopathology, Lancaster, v.93, p.535-546, 2003. 
ROSSI, A. D. Situação atual da produção de maracujá no Estado de São Paulo. In: SAMPAIO, A. C. et al. (Org.). Seminário sobre o manejo no controle do vírus do endurecimento dos frutos (PWV) do maracujazeiro. Jaboticabal: Gráfica Multipress, São Paulo, 2005. p.9-20.

SANTOS, D. M. Efeito do silício na intensidade da cercosporiose Cercospora coffeicola (Berk. \& Cooke) em mudas de cafeeiro (Coffea arabica L.). 2002. 43f. Dissertação (Mestrado em Agronomia)Universidade Federal de Lavras, Lavras, 2002.
SANTOS, H. A. A. dos; MAY de MIO, L. L. Controle preventivo e curativo da ferrugem do álamo em viveiro. Floresta, Curitiba, PR, v. 37, n. 3, p.315325, 2007.

WALDEMAR FILHO, P. de C.; CAMARGO, F. P.; ALVES, H. S. Algumas sugestões para a expansão da agropecuária orgânica no Estado de São Paulo. Informações Econômicas, São Paulo, v.37, n.6, 2007. 